\title{
FILOSOFÍA DE LA DANZA, UNA APROXIMACIÓN DESDE LA ESTÉTICA MODAL
}

\author{
Sara Reyes Acosta \\ reyes.asara@gmail.com
}

\section{RESUMEN}

Este artículo parte del deseo de plantear, explorar y poner en juego el rico dispositivo filosófico-metodológico de la Estética Modal ${ }^{1}$, así como reflexionar qué hay de enigmático, metafísico y a la vez mundano y necesario en la experiencia estética, en aquello que nos inquieta del arte como fenómeno en general y en especial de los objetos artísticos como cuerpos que se disponen hacia la reflexión filosófica. Desde una visión de la estética profundamente pragmática pretendemos guiar nuestra curiosidad hacia los flujos y transformaciones que se han dado en el mundo de la danza como materialización de las derivas culturales, políticas, sociales o espirituales para afirmar que a pesar de no responder a preguntas, así como sucede con la filosofía, el arte es capaz de plantear, suscitar y generar tanto espacios físicos como virtuales de reflexión y persistencia.

Palabras Clave: Estética Modal, fenómeno, transformaciones, cuerpo, danza, persistencia, experiencia estética.

\section{PHILOSOPHY OF DANCE, AN APPROACH FROM MODAL AESTHETICS}

\section{Abstract}

This paper comes from the desire to pose, explore and put into play the rich philosophical-methodological device of Modal Aesthetics as well as to reflect what is enigmatic, metaphysical and at the same time mundane and necessary in the aesthetic experience, in what concerns us about art as a phenomenon in general and especially of artistic objects as bodies that are disposed towards philosophical reflection. From a deeply pragmatic vision of aesthetics we intend to guide our curiosity towards the flows and transformations that have taken place in the world of dance as a materialization of cultural, political, social or spiritual drifts to affirm that despite not answering questions, as it also happens with philosophy, art is capable of raising and generating both physical and virtual spaces of reflection and persistence.

KeYwords: Modal Aesthetics, phenomenon, transformations, body, dance, persistance, aesthetic experience.

DOI: http://doi.org/10.25145/j.laguna.2018.43.004 


\section{INTRODUCCIÓN}

¿De qué maneras podemos recurrir a la teoría estética como fundamento analítico y metodológico, como soporte o como herramienta necesaria a las prácticas artísticas, sabiendo que el arte surge como una necesidad «no útil» ${ }^{2}$, en términos de Paul Valery?

Este trabajo plantea una aproximación analítico-pragmática, desde un punto de vista estético y fenomenológico, a la Estética Modal desde la necesidad de plantearnos de qué manera podemos establecer una mirada a la danza en tanto práctica artística. Esto surge desde la necesidad de investigar modos de relación posibles entre las unidades del pensamiento y la praxis y plantear de qué diversas formas puede la teoría estética inspirar, apoyar, nutrir las prácticas artísticas y viceversa. Así, desde temprano, declaramos la necesidad que existe en retroalimentar ambas, sin olvidar, en términos hartmantianos ${ }^{3}$, que son entidades de índole diferente.

El punto de partida está principalmente guiado desde un recorrido histórico-ontológico-estético del arte centrándonos especialmente en los periodos de transformación sobre los modos de relacionarnos con este y en definitiva con nosotros y nosotras mismas. Para ello la Estética Modalde Jordi Claramonte ha influido especialmente en la dirección, contenido y estructura del trabajo y ha servido de material base del que partir, de herramienta de análisis y de guía metodológica. Los conceptos modales y

${ }^{1}$ No solo referida a la obra de Claramonte J. Estética Modal, Tecnos, Madrid, 2016, sino también a toda una concepción concreta de la Estética. Claramonte la define como «una teoría de la distribución, una teoría de los modos de relación a través de los cuales se especifica y se organiza nuestra sensibilidad y nuestra inteligencia. Una teoría que combina en lo efectivo diferentes proporciones de necesidad y contingencia, posibilidad e imposibilidad».

${ }^{2}$ La necesidad del arte, defiende Paul Valéry, viene dada desde su naturaleza trascendente. De este modo, la danza surge, partiendo de su naturaleza fenoménica, de un pensar trascendental que ha comprendido que el arte sucede como una necesidad no útil. Es decir, su necesidad viene dada de modo axiológico desde la emergencia de un novum categorial. Vinculando este hecho con la Teoría de estratos de N. Hartmann, podemos diferenciar la importancia de los grados ontológicos de aquello que hay. El arte necesita de los estratos más básicos de nuestra vida pero surge desde una incertidumbre bien diferenciada de las necesidades básicas. «Nuestros actos útiles son finitos. Van de un estado a otro", por ello no podríamos, en tanto seres humanos psíquicos, sociales y espirituales, llevar una vida estrictamente ocupada y limitada únicamente al cuidado de nuestro cuerpo orgánico para vivir, atendiendo únicamente a «lo necesario». Nuestra autonomía modal surge de este novum categorial como una lucha de poder hacia nuestras libertades ontológicas individuales y colectivas. Por ello construimos cultura, porque a diferencia de los seres meramente orgánicos, somos capaces de elaborar valores que organizan también nuestra vida humana, redistribuyendo axiológicamente aquello que necesitamos. Tal como afirma en L'âme et la danse»: "El hombre es ese animal singular que se mira vivir, que se da un valor, y que coloca todo ese valor que le gusta darse en la importancia que concede a las percepciones inútiles y a los actos sin consecuencia física vital» (p. 176).

${ }^{3}$ Nicolai Hartmann en la Introducción a su obra póstuma Estética advierte: «El filósofo inicia su tarea donde ambos abandonan el asombro de lo que experimentan a los poderes de la profundidad y del inconsciente. El filósofo sigue el rastro de lo enigmático, analiza. Pero en el análisis cancela la actitud de la entrega y del éxtasis. La estética es exclusiva de quien tiene una actitud filosófica. A la inversa, la actitud de la entrega y el éxtasis cancela la filosófica o, cuando menos, la perjudica» (p. 6). 
categoriales que de él emergen están en diálogo con las tesis en el libro mencionado planteadas y con toda una tradición un tanto dispersa pero comunicante desde la biología y las matemáticas hacia la política, la fenomenología o la teoría de la performance. Lo interesante ha sido, más que rescatar los planteamientos científicos o culturales que estas visiones defienden, aplicar vasos comunicantes entre aquello que tienen en común o que puede ser servir a la reflexión. Se pretende así una honesta aproximación a sus planteamientos estético-filosóficos, que componen todo un entramado complejo y a la vez vital de relaciones, extrapolables no solo a lo referente con la obra de arte y los procesos artísticos sino a toda organización vital que quiera ser pensada en términos filosóficos. El planteamiento que de él se genera nos llevará a cuestionar de qué modo se han generado comienzos y rupturas en la tradición estética y sobre todo cuestionarnos de qué manera podemos hoy en día preguntarnos por el problema crucial de la autonomía en el arte acudiendo a las exigencias de nuestro tiempo.

El principal impulso que mueve este ensayo estará centrado en perseguir una línea dinámica entre los periodos y procesos artísticos, así como partir de piezas y autores/as concretas para abrir espacio a preguntas filosóficas que de las mismas emergen. Desde la curiosidad que esta misma dinámica incita se abre espacio para preguntas como ¡es posible objetivar la naturaleza efímera de la danza?, ¿cómo sabemos cuándo ha llegado su fin?, ¿cómo se retroalimentan la teoría y la práctica?, ¿es necesario un diálogo entre ellas?, ¿en qué momento nos encontramos?

El ensayo está inspirado por una parte por toda una tradición filosófica que ha defendido una idea modal de la estética o en general de la filosofía por autores clásicos y contemporáneos tales como Georg Lukács, Nicolai Hartmann, John Berger, Maurice Merleau Ponty y el propio Jordi Claramonte; y otra, de carácter más explícitamente dancística o performática por investigadores/as, dramaturgos, coreógrafos y teóricos de la danza actuales, entre los que podemos nombrar a André Lepecki, Laurence Louppe, Roberto Fratini, Anna Pakes o Jaime Conde Salazar en tanto que nos aportan una visión directa y dinámica sobre los procesos artísticos y las reflexiones que brotan de tales ciclos de creación o emergencias e incluso en ocasiones urgencias de la contemporaneidad. De este modo intentaremos combinar aquellos momentos que requieren más concreción teórica y otros que abren y exigen de sí mismos el camino a la práctica.

Especialmente queremos rescatar el concepto de modalidad comprendido como aquello que hay en medio de la relación entre supuestamente dos entidades, tales como objeto-sujeto, artista-obra e incluso prácticas artísticas-experiencias estéticas. Para ello, tanto Nicolai Hartmann como Jordi Claramonte retoman el pensamiento modal de los antiguos griegos, anterior a Sócrates. Los modos ayudaban a comprender la raíz de la naturaleza, su motor, su devenir. De esta manera basaron sus teorías sobre el principio material de la naturaleza, la physis, tratando de explicar qué era aquello que constituía y podía explicar los fenómenos y los seres naturales, proponiendo, de cierto modo, un quebrantamiento de las formas míticas. Es cierto que consideraban la naturaleza como totalidad, en tanto sustancia absoluta, permanente e inmutable, pero su interés radicaba en las formas de expresión de la sustancia y en particular en los estados y propiedades de la misma. En definitiva, en la explicación de los cambios que dependen de esta, aquellos que padecen todos los seres. 
Hartmann encuentra también en Aristóteles ricas alusiones al pensamiento modal; en su referencia afirma: «Es fácil ver que el mundo real no se agota en una única y uniforme forma de ser, sino que constituye, antes bien, una gradación. Ya en Aristóteles se encuentra la idea de un orden gradual que marcha a través del mundo entero, que va desde la materia ya especializada, pasando por el cuerpo físico, el cuerpo orgánico y el ser vivo animado, hasta el ser vivo político, el hombre, que por su lado puede alcanzar grados todavía más altos» ${ }^{4}$. Así pues, el pensamiento modal rechaza el dualismo y las oposiciones binarias, para, sin anularlo, intentar explicar lo que hay en medio de esta tensión. En términos de Hartmann: "La potencia y el acto formaban una pareja cerrada de contrarios, que no parecía menesterosa de complemento mientras no se dudase de la fuerza predeterminante del eidos ${ }^{5} \aleph^{6}$. El cambio que es interesante para la Estética Modal podríamos decir que tiene lugar especialmente de mano de la ciencia moderna cuando se toman en cuenta las oscilaciones entre orden y caos, en términos de la biología, o cuando se comienzan a tener en cuenta las fluctuaciones, en términos químicos. El hecho de acoger y recuperar la Teoría de las mutaciones por la cual se habían preocupado ya los antiguos impulsará esta manera de pensar los fenómenos como seres modales. El romántico Goethe fue ejemplo de la defensa del pensamiento modal sobre el arte considerando a los sistemas artísticos como seres dinámicos que fluctúan, se movilizan, bien hacia lo centrípeto, buscando un centro, o hacia lo centrífugo, alejándose de él. Se hace por tanto latente esta importancia de explicar la propia causalidad de la naturaleza bajo términos modales, que se ajusten de forma coherente y honesta a los procesos de cambio, de orden, de lucha y de dependencia. Podemos aún llevar esta realidad más allá afirmando que también en la estética, así como en los demás procesos vitales, será necesario un modo de pensar que se adecúe a los estados por los que este mismo pasa, desde el nacimiento, la reproducción, la muerte, el estancamiento, el bucle, la repetición, el agotamiento y, en los casos más exitosos, la fluidez.

Las más de las teorías metafísicas han intentado, justamente, derivar el mundo de un principio. En ello estuvo su error. Pasaron por alto que los principios mismos son complejos y están en sí estratificados, y que el mundo tiene por ello necesariamente su estructura estratificada ${ }^{7}$.

La labor de la fenomenología es también importante de cara al pensamiento modal en tanto que mantiene su interés por trabajar con conceptos relacionales $y$, sin huir del problema del dualismo, plantea una alternativa desde la deconstrucción. El concepto de Carne en Merleau Ponty es realmente útil para ilustrar este hecho. Dentro de su campo de la fenomenología intenta, del mismo modo que la teoría estética, establecer modos de relación. La carne es tratada de modo teórico como un

\footnotetext{
${ }^{4}$ Hartmann, N. Introducción a la Filosofía, UNAM, México p. 120.

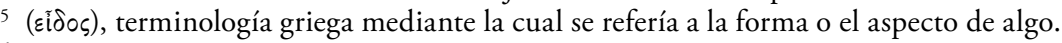

${ }^{6}$ Hartmann, N. Ontología II, FCE, México, 1956, p. 21.

7 Hartmann, N. Introducción a la Filosofía, CEF, México, 1961, p. 125.
} 
concepto relacional, intersensorial. Mediante el estudio de la percepción Merleau Ponty pretende recoger la relación constante que se establece entre el experimentador y lo experimentado, entre la mano que toca el mundo y la mano que se toca, que es tocada. No hay separación para Ponty entre yo y el otro, cuerpo y espíritu, sino que es intercambio de mí con el mundo, del cuerpo fenoménico con el cuerpo objetivo, de lo que percibe con lo percibido. «Hay que pensar la carne, no a partir de sustancias como cuerpo y espíritu, porque entonces sería unión de contradictorios, sino como elemento, emblema concreto de un modo de ser general ${ }^{8}$. El cuerpo, al presentar esta dualidad, no dualismo, es entendido como un quiasmo, una partición, y no como una división. Su distinción recae en que no es un concepto estático y cerrado sino que inicia un movimiento relacional. Lo interesante para ambas, tanto fenomenología como estética, es estudiar lo que está en ese punto intermedio de lo uno y lo otro, la tensión que se crea en el terreno del entre. El concepto del quiasmo tanto para la estética como para la fenomenología merleaupontiana nos permite pensar la dualidad sin necesidad de disolverla sino de establecer relaciones de entrecruce, de complementariedad e incluso de sobreposición o reversibilidad.

Inspirándonos y retomando de dichos autores citados esta visión pretendemos defender que sea el arte en general y el objeto artístico en particular un ser modal y no una entidad cerrada en sí misma. Necesitamos así adoptar una comprensión más atenta que no pretende dar por sentado el problema de lo subjetivo-objetivo, tan presente en la discusión filosófica y sobre todo estética del artista como creador y el público como receptor, sino que realmente la atiende, situándonos en la compleja trama de relaciones que la nutren.

\section{LA DANZA COMO FENÓMENO}

La danza existe como perpetuo punto de fuga. En el momento mismo de su creación desaparece. Todos los años de formación de un bailarín en el estudio, toda la planificación del coreógrafo, los ensayos, la coordinación de escenógrafos, compositores y técnicos, la recaudación de dinero y la convocatoria de un público, todo ello es tan sólo una preparación para un acontecimiento que desaparece en el acto mismo de su materialización. Ningún otro arte es tan difícil de atrapar, tan imposible de mantener (Siegel, 1973, 1).

Por ahora nos centraremos un poco más de lleno en indagar sobre lo distintivo de la danza (así como las denominadas artes escénicas o performativas) ${ }^{9}$, en aquello que la caracteriza y la singulariza respecto a otras formas artísticas. Si queremos llevar a cabo un análisis de sus obras tendremos que atender a su carácter

${ }^{8}$ Merleau-Ponty, M. Lo visible y lo invisible, Seix Barral, Barcelona, 1970, pp. 181-183.

${ }^{9}$ Lo performativo, como bien lo anuncia Jaime Conde Salazar en La danza del futuro remite al «poder de producir maneras posibles de estar vivo». Cfr. J. Conde Salazar, Continta me tienes, Ed. Madrid, 2018, p. 70. 
ontológico y no muy tarde nos daremos cuenta de lo escurridizos que pueden resultar sus elementos al pretender teorizarla. En especial atenderemos a algunos aspectos que tienen que ver con su naturaleza ontológica y su forma de relacionarse.

La naturaleza fenoménica del cuerpo es de entrada una realidad de la que partir. Para la danza el cuerpo es su realidad primera, es para ella tanto carne como corporeidad y, a diferencia de la pintura, la escultura o la literatura, tales cuerpos están vivos y presentes. Las denominadas artes plásticas hacen un uso de su cuerpo en tanto metacuerpo, es decir, el cuerpo posibilita un producto estético. El resultado es aquello sobre lo que el cuerpo ha intervenido y transitado. Ahora bien, en las artes performativas el cuerpo es el componente indispensable y fundamental, es presencia y presente, es principio y fin. Sin cuerpo no hay danza, incluso cuando se quiera hablar de la ausencia de movimiento se necesita de un cuerpo. De entrada partimos por tanto de una situación específica: la presencia de vida humana. A diferencia de otras formas de expresión artísticas o productos estéticos, la danza tiene presente un componente orgánico y expresivo por sí mismo en el ahora, es por ello que sea el cuerpo su realidad primera y no solo posibilitante o instrumento de la realización de la obra. Además, dicho producto es posiblemente el más abstracto de todos. Una obra de danza, incluso aquellas que en el plano de lo efectivo son repertorialmente más potentes o hacen mayor uso de su carácter repertorial, es efímera en sí misma. Puede ser grabada, fotografiada, archivada, se puede escribir sobre ella, pero nunca será, y en esto nos ponemos un poco platónicas, la obra en sí misma, sino porciones, fragmentos, síntesis, alusiones de ella. Es como si la obra de alguna manera siguiera dependiendo de todos los elementos por los que es concebida y en el momento en el que su realidad más básica, como es que la misma presencia del cuerpo no tenga lugar, quizás deberíamos dejar de hablar de una obra escénica.

Otra de las complejidades que presenta son sus consecuencias, lo que desencadena de modo causal una vez acabada. La obra desaparece tal como apareció, dejándonos únicamente con la experiencia de esta, en el mejor de los casos catártica y en el peor de los casos indiferente. Pero aunque nos haya conmovido y podamos haber obtenido un conocimiento provechoso de ella, es ya pasado. Este hecho remarca que el arte sea experiencia, especialmente en la danza, ya que la experiencia que tenemos de ella es más difícil de archivar. La obra tiene vida en sí misma, es autoexpresiva $y$, en tanto que es performática, es capaz de transformar la realidad con el mismo acto de su aparecer. Por ello decimos que es profundamente fenomenológica, porque construye su sentido mediante su presencia. Su capacidad de relacionarse y trascender moviliza el silencio y la quietud de la realidad y aporta el silencio necesario ante el ruido cultural que contamina en muchas ocasiones nuestra capacidad de tener una experiencia estética del mundo. Esta naturaleza distintiva puede ser sin duda una virtud en sí misma, y, al igual que en otras formas de expresión artística, lleva consigo los mecanismos necesarios para poder sostenerse sin la necesidad de una institución que la apruebe o que considere qué puede ser denominado como danza y qué no. En su máxima autoorganización, autopoiesis, es autónoma aunque dependiente de quienes la observan y quienes la nutren.

El cuerpo es por tanto inobjetivable, de objetivarlo caeríamos en la torpeza de hacer únicamente un uso instrumental y sistemático del mismo. Lo que pre- 
tendemos al tratar al cuerpo como fenómeno no es acudir a la Historia, sino a las historias. Como hemos visto bajo el pensamiento modal, cuando convertimos un fenómeno en idea y dejamos de articularla con el mundo de la praxis, esta pierde su condición modal. El cuerpo es también expresado a partir de los modos, los cuales intervienen como hemos visto en nuestros espectros de vida y representan las diversas funciones y modos del ser. Por tanto lo distintivo de la danza, lo que radicalmente la diferencia de las demás formas artísticas, es su imposibilidad de acotarse y archivarse, así como su efímero aparecer. A diferencia de las obras de arte "estáticas», que nos permiten una mayor paciencia y disponibilidad para ser analizada, la danza aparece y desaparece. Tiene en común con los fenómenos/seres naturales este modo de ser efímero, en tanto que nos proporciona una experiencia estética temporal. No nos permite, a diferencia del cine o la pintura, paralizarla o poder hacer zoom en un detalle sin que deje de suceder lo que está sucediendo «de fondo». Somos invitados/ as de principio a fin.

A pesar de que las aportaciones de la fenomenología no sean de índole precisamente estética, han permitido de manera indudable toda una articulación del pensamiento, un modo de ver y de ser que abre camino a un pensar estético. A partir de la fenomenología nos acercamos, mediante su minuciosa atención, al aparecer y el suceder de las cosas, a defender el ser modal en tanto corporeidad, y permitir el surgimiento de conceptos relacionales como el de Carne y Quiasmos en Merleau Ponty. También es cierto que la naturaleza fenoménica de la danza y el carácter temporal de sus elementos, que cesarán una vez que los cuerpos reposen, ha sido uno de los motivos ${ }^{10}$ para que muchos/as teóricos/as hayan encontrado dificultades o impedimentos a la hora de elaborar una Teoría de la danza. Afirmaba Paul Valéry en el diálogo L'âme et la danse esta presencia y ausencia que la caracteriza: «Elle célébrait tous les mystères de l'absence et de la présence; elle semblait quelquefois effleurer d'inneffales catastrophes!... Mais à présent, pour rendre grâces à l'Aphrodite, regardez-la. N'est-elle pas soudain une véritable vague de la mer?»" ${ }^{11}$ Aquí Valéry,

${ }^{10}$ La institucionalización de la danza ha provocado también su desarticulación con lo pragmático, excluyendo a la danza (así como ha ocurrido con las demás artes) de las esferas de la vida e impidiendo, debido a su «elitización", un pensamiento móvil sobre ella. Como decimos, pudo ser debido a las presiones del Régimen, o bien por la propia danza en tanto sistema repertorial al haberse creído a sí misma autosuficiente. Nos referimos a aquella que solo tiene su razón de ser para un público en tanto espectáculo y que únicamente puede ser producida en un teatro. En último término ambas obedecen a las mismas lógicas, suficientes para que se dé lugar a un desinterés generalizado por un pensamiento filosófico sobre la danza, y lejos de comprender que la misma no está más allá de nuestras vidas ordinarias, sino intrínseca a ellas e insertada profundamente en su ser. Tal y como plantea J. Conde Salazar en La danza del futuro: «La danza del futuro no necesita pedir permiso a ninguna instancia patriarcal para existir y realizarse. Por eso la danza del futuro siempre pone su capacidad de producir conocimiento al servicio del mundo [...], la danza del futuro se disuelve en la realidad. Integrada en la vida como una herramienta de uso cotidiano, sirve principalmente para compartir conocimiento libremente, para generar posibilidades de entender lo que somos y hacemos", op. cit., p. 70.

${ }^{11}$ ValÉry, P. L'âme et la danse, Éditions de la Nouvelle revue française, Paris, 1921 pp. 1-32. 
mediante su pensar poético, roza lo enigmático del pensamiento presocrático, como Heráclito, para el que no podemos bańarnos dos veces en un mismo río. La danza sería también esa realidad del transcurrir. La danza significó para él fuente de inspiración hacia un pensar filosófico concreto. Este fenómeno de la danza que rescata Paul Valéry nos posibilita pensar que la danza no es únicamente aquella concepción que hemos heredado de la academia, ni aquella que cumple o agota su condición de ser con unas necesidades hegemónicas burguesas. Danza pueden ser infinitas cosas: "Tapónense los oídos, si se atreven. No vean más que esas manos. Mírenlas actuar y correr sobre la estrecha escena que les ofrece el teclado. ¿No son esas manos danzarinas que, también ellas, han debido ser sometidas durante años a una disciplina severa, a ejercicios sin fin? $»^{12}$. En otros términos, «la danza del futuro puede suceder en cualquier contexto, situación, momento o relación $»^{13}$. Incluso, sin necesidad de una «disciplina severa». Afirmar la danza como disciplina corre el gran riesgo de quedar desarticulada de la vida práctica (no por ello «útil») y quedar cerrada en sí misma. Así como por el hecho de categorizarla como disciplina esperamos algo de ella, algo que esté a la altura de una «disciplina». Y este «estar a la altura» es en ocasiones sinónimo de un discurso hegemónico dado desde fuera de la misma disciplina.

\subsection{Cómo TeOrizar la DANZA PARTIENDO DE SU NATURALEZA EFÍMERA: LA DANZA COMO ARCHIVO}

Su naturaleza efímera nos lleva directamente a pensar en la problemática existente entre la posibilidad de elaborar o llevar a cabo una filosofía de la danza, o un pensar orientado hacia la teoría de la misma. Es decir, nos lleva a plantear la cuestión de cómo materializar su ser fenoménico, si es que esto fuera posible. Sin embargo, esta imposibilidad ha sido un límite que creadores/as contemporáneos han querido traspasar y han hecho efectivos sus intentos en la escena. André Lepecki analiza casos concretos que persiguen la idea de archivo en la danza en su ensayo «El cuerpo como archivo: el deseo de recreación y las supervivencias de las danzas» ${ }^{14}$.

Uno de los síntomas de esta búsqueda o rescate por el pasado, de deseo de la danza por su materialización y por su posibilidad de permanencia y reproducción, son las diversas recreaciones llevadas a cabo las últimas décadas por bailarines/as y coreógrafos/as a partir de artistas representativas de la danza del siglo pasado. Aquí podemos encontrar no solo un caso de nostalgia, admiración u homenaje, sino un sintomático retorno a lo necesario y un cuestionamiento de sus límites: devolver a la danza contemporánea un peso repertorial, así como luchar o jugar con su naturaleza

12 Ibidem, p. 185.

13 Conde Salazar, J. Op. cit., p. 51.

${ }^{14}$ LePECKI, A.: El cuerpo como Archivo: El deseo de recreación y las supervivencias de las danzas, en Naverrán, I. y Écija, A. (eds.). Lecturas sobre Danza y Coreografía, (pp. 59-81), Artea, Madrid, p. 77. 
efímera. Han sido también numerosos los festivales y conferencias llevados a cabo en torno a la temática durante las últimas décadas, entre ellos podemos citar el festival Re:Move en el Kaai Theater de Bruselas en torno a la recreación y el archivo de la danza o el archivo de danza de Leipzig titulado Archive/Practice en 2009. En especial las piezas que analiza Lepecki en el ensayo citado parten de la materialización de la idea de que un cuerpo pueda ser en sí mismo un archivo. Este hecho se hace efectivo en algunos de los ejemplos mediante la presencia de un otro que observa, que es tanto cuerpo, performer, público como archivero. Otra forma de considerar al cuerpo como archivo, y quizás más interesante, es que el archivo sea tomado como un dispositivo móvil capaz de recrearse o reedificarse. Es útil la concepción de Foucault que retoma Lepecki sobre el archivo cuando dice: «No es una cosa, no es un recipiente, no es un edificio, ni una caja, ni un sistema de clasificación ${ }^{15}$, en cambio, el archivo debe ser comprendido como «el sistema general de la formación y de la transformación de los enunciados» ${ }^{16}$. Esta simple enunciación es suficiente para afirmar que el archivo puede ser considerado en sí mismo un sistema dinámico y que debido a su dinámica es capaz de generar nuevas posibilidades. $\mathrm{O}$ como afirma Lepecki, «la coreografía es un sistema archivístico-corpóreo que también convierte los enunciados en acontecimientos corpóreos y objetos cinéticos» ${ }^{17}$. De este modo, la danza como archivo debe ser entendida no como una colección estática de biblioteca o como un mero ejercicio burocrático y sistemático, sino que el archivo debe servir como generador y activador de procesos, ya sea para retomar su pasado o para generar relecturas y futuros, siempre a partir del cuerpo. La naturaleza de la danza nos recuerda que esta solo tiene lugar en el hacer, y con ello no nos queremos referir al sintomático y enfermizo modo de producir de nuestro sistema capitalista, sino a que el archivo debe ser entendido únicamente desde la presuposición de que «la danza solo se puede transmitir de cuerpo a cuerpo, por eso, en vez de archivo, se habla de repertorio; en vez de clasificar obras encajándolas en una estructura estética creada a priori, las obras se encarnan y rehacen ${ }^{18}$.

La razón de ser del archivo es por tanto mantener la posibilidad de poder acceder a él coreográficamente, es decir, desde la praxis, la acción. Se asume que a pesar de partir de una supuesta objetividad (el archivo), la danza está abocada a la transformación en tanto que es capaz de poner palabras en acciones y las acciones en acontecimientos. Además, aceptar la capacidad de la danza como archivo es para Lepecki la afirmación de que la presuposición de un «original» en el arte es siempre errónea e incompleta. Aunque pudiera parecer que el archivo hace una simple función mimética de la obra, Lepecki defiende la recreación como «un modo privilegiado de efectuar o actualizar el campo inmanente de inventiva y creatividad de una obra» ${ }^{19}$. Y tal proposición «implica que debemos tratar cualquier obra de arte, por ejemplo

\footnotetext{
15 Ibidem, p. 69.

16 Foucault, M. La arqueología del saber, Siglo XXI, Buenos Aires, 2002, p. 130.

${ }_{17}$ Ibidem, p. 69.

18 Conde Salazar, J. Op. cit., p. 63.

19 Ibidem, p. 77.
} 
una pieza coreográfica, como un ente en cierto modo autónomo en sus planos de composición, expresión y consistencia [...]. Plantear la autonomía de la obra de arte implica reconocer una capacidad específica en cualquier coreografía para apelar, invocar o incluso exigir actualizaciones ${ }^{20}$.

El archivo por tanto debe estar al servicio de la danza, ya que es desde ella desde donde este tiene sentido y lugar. Del mismo modo la acción que se genera desde el archivo actúa con una relación de dependencia y autonomía, capaz de autogestionarse y autoproducirse. Ambos, cuerpo y archivo tienen en común su dispersión, en términos de Lepecki, a la vez que su capacidad transformadora. Es por ello por lo que no hay realmente una actividad mimética, sino profundamente poiética. De alguna manera, el uso del archivo en la escena es un intento radical de hacer efectivo no solo aquello que desaparece, sino aquello que siempre vuelve, aquello que siempre está presente o que puede gestarse. El archivo aboca a una transformación sobre el modo de mirar convencional de la danza como algo hermético y efímero. La danza es también posible, y de hecho es más honesto pensarlo, como proceso. Por tanto la danza, más que obras, produce procesos que se comparten y se elaboran mediante la transformación, mediante «excorporaciones e incorporaciones» en términos de Lepecki.

Retomando la problemática entonces de cómo poder alimentar teoría y praxis, Roberto Fratini defiende que danza y teoría no han estado nunca tan estrechamente relacionadas como hoy. Ahora bien, ¿cómo es esta relación? El cuerpo se ha convertido en un terreno de curiosidad para muchos, que tras largo tiempo de estar deshabitado, nos hemos preocupado en ocupar. Desafortunadamente la simbiosis teoría-praxis está actualmente confundida hasta el punto de tener que coexistir ambas en un mismo tiempo. El problema con que podemos encontrarnos es que debido a esta simultaneidad y velocidad de consumo de nuestros modos capitalistas de relacionarnos con el arte, estemos impidiendo el mismo proceso predicativo de este.

La danza corre el riesgo de perder en esta yuxtaposición teoría-praxis, argumentación teórica-despliegue fenoménico, su facticidad y su carácter autónomo en tanto que dejamos de bailar ${ }^{21}$ y dedicamos horas a hablar de algo que aún no ha pasado o que ya pasó y no necesita toda una justificación o explicación. La danza es en sí misma predicativa. Con ello no decimos que no pueda darse un planteamiento estético por el/la artista, o que el/la esteta sea incapaz de generar una obra o proceso creativo, sino que, al menos, la actitud de ambas no puede darse al unísono, ya que se entorpecerían. Este fenómeno nos recuerda a la experiencia de la categoría de la Catarsis que defendían los clásicos. La catarsis y el gran representante de la tragedia griega Esquilo nos recordaban el principio del pathei mathos, que afirma que en tanto somos afectados por padecimientos sentimentales de nuestra propia vida, nada

${ }^{20}$ Ibidem.

${ }^{21}$ Es conveniente aclarar el uso de «baile» o danza. Esta sucede de muy distintas maneras y puede adquirir distintos formatos, tantos como el/la propia intérprete desee. En este sentido la danza no tiene una forma determinada ni es una disciplina cerrada. 
podemos aprender sobre ellos, es únicamente posible aprender de los padecimientos ajenos o de los nuestros una vez que hayan cesado, ya que no pueden darse a la vez el dolor y el aprendizaje. Esto viene a afirmar que toda acción desencadena consecuencias que nos afectan, aunque en un primer instante no podamos apreciarlas. El arte por tanto a lo que se dispone es a generar posibilidades de recepción, y en raras ocasiones la intencionalidad del artista, incluso cuando los valores hayan madurado, coincide con aquello que los demás reciben, ya que los demás no son sujetos neutros ni el artista es diferente en tanto condición ontológica al resto.

\section{PENSAR LA CONTEMPORANEIDAD}

Toda experiencia estética es, al cabo, experiencia de un extrañamiento y de una reorientación, de un desacoplamiento y de la ilusión o promesa de un reacoplamiento (J. Claramonte).

\section{- Ejes como ojos}

Pensar la contemporaneidad supone pensar a partir del pasado y de las herramientas de las que disponemos para pensar el fenómeno del devenir. Esto supone pensar los límites con los que el arte juega continuamente a los que la estética ha prestado desde sus orígenes especial atención. Con ello queremos aludir a la dialéctica que subyace a los modos y a los ejes de tensión necesarios para mantener viva una experiencia estética, especialmente en aquellos momentos en los que pareciera estar rozando el borde del precipicio o haber incluso llegado a él.

Aunque ya había en los modelos clásicos, especialmente en Aristóteles, alusiones a los límites necesarios para que pudiera darse la experiencia estética, optando por un término medio de esta dialéctica y situando las categorías estéticas inherentes al objeto, estos límites radicaban en opuestos tensados por una dualidad. No obstante, hoy en día necesitamos ampliar estas herramientas de análisis en tanto que partimos de una situación bastante más dispersa y las polaridades se han multiplicado. Afirma J. Claramonte: «El quehacer distintivo de cada artista consiste en gran medida en determinar la proporción, la ecuación que regula el equilibro entre esas $-\mathrm{y}$ otras- polaridades ${ }^{22}$.

En esta tensión, asegura el filósofo y compositor Leonard B. Meyer, la incertidumbre es un componente indispensable para que pueda realizarse la experiencia estética. De ser totalmente aprehensible se quedaría completamente ligada a su plausibilidad, ahí donde recae el peso repertorial, siendo incapaz de provocarnos. En cambio, si pone en marcha su disposicionalidad sin mirar atrás, corre el riesgo de dejarnos tirados y ver cómo se aleja, dejándonos una incertidumbre un tanto

22 Claramonte, J. Estética Modal, p. 159. 
indeseable. ¿Está el arte contemporáneo jugando a esta escapada?, ¿es su pretensión agotarse?

Mediante la Teoría de diamantes ${ }^{23}$ se pretende hacer justicia a la complejidad de relaciones intermodales que operan en la experiencia estética. Para ello, necesita más de dos polaridades o ejes de tensión binaria. La riqueza de los diamantes radica en la convergencia y convivencia de, en un principio, cuatro tesis: aceptación, oposición, rechazo y proposición, que se asumen como una única realidad y no como una sucesión de estados. Este darse a la vez es lo que permite tener en cuenta los factores que posiblemente estaban quedando fuera o que éramos incapaces de ver. Además, estos cuatro vértices para poder mantener una forma diamantina necesitan de dos quiasmos que los articulen, es decir, una partición no excluyente, generando por tanto seis formas de relación entre esos cuatro elementos. «Por un lado hay un eje que separa y une la posición con la oposición y por otro lado hay otro eje que hace lo propio con los sistemas de aceptación y los sistemas de rechazo ${ }^{24}$.

Lo interesante, más que resolver el conflicto, es atender a los modos transitorios entre lo que se revela y lo que se esconde, el término medio aristotélico entre el quedarse corto o el rebasarse, así como observar que el modo de relación no tiene por qué ser proporcional entre dos polaridades y que las relaciones en la teoría de diamantes son también generativas, y, retomando el término merleaupontiano, quiasmáticas. Con ello queremos reflejar que nuestra situación contemporánea necesita de herramientas complejas capaces de integrar las complicaciones que nos surgen a la hora de analizar nuestro tiempo, y que seguro supusieron un problema para cualquier temporalidad, porque, como bien afirma Jaime Conde Salazar, «todo está todo el tiempo», es decir, que no hay una estructura narrativa lineal.

El diamante nos refleja que hay al menos dos relaciones posibles de producción: que un acto genere un objeto y que un objeto genere un acto. La primera ha estado más presente en la forma clásica de concebir el arte, como por ejemplo cuando un/a coreógrafo/a genera una pieza de danza y esta se convierte en «su» "producto". Ahora bien, podríamos considerar que un objeto, como puede ser el archivo de la obra que ha sido ya "creada", pueda reconcebirse en la praxis dando pie a una nueva posibilidad. Esta forma de concebir el fenómeno del arte está más cerca de comprender las piezas como procesos y no como obras autónomas cerradas en sí mismas, ya que el proceso implica una codependencia con un otro (factor o cuerpo). Este no agotarse en sí mismo tiene además una direccionalidad móvil, no necesariamente lineal. Por ello decíamos que la danza como archivo se dispone hacia el futuro para poder seguir desarrollándose, para incluso volver a su punto inicial o para ir hacia ninguna parte.

23 Tal teoría es expuesta en la Estética Modal y propuesta por Rudolph Kaehr (1945-2016), uno de los mayores expertos en Teoría de Diamantes, Teoría de la Policontexturalidad y otras Teorías de sistemas. Se pueden ver sus trabajos en la web http://www.thinkartlab.com/.

24 Ibidem, p. 162. 
Ahora bien, algo que debemos tener en cuenta y que tanto Hartmann como Claramonte remarcan es que no hay intención alguna posible de que el/la artista al producir el objeto pueda producir valores como quien esculpe un material. "Lo que puede hacer es coincidir con ellos (los valores), verlos - como quien ve una apuesta- $\mathrm{y}$ orientar su producción en función de ellos ${ }^{25}$. De esta manera negamos la autoría total de la obra de arte, así como su total dependencia con el artista en tanto «creador». El artista sería más bien un generador de valores, un posibilitador. «Para decepción de los más entusiastas propagandistas, el acto de recepción estético no es nunca el producto de un objeto-estructura, en el mejor de los casos, el acto de recepción coincide con dicho objeto-estructura $»^{26}$.

Por consiguiente, debe estar en el objeto operando una dialéctica entre la potencialidad de valores "maduros», en términos de Hartmann, así como aquella incertidumbre que aseguraba Leonard B. Meyer o ausencia de clausura para que podamos completar o dotar de sentido lo que experienciamos. Cuando no hay un equilibrio entre estas realidades, se produce lo que Meyer denomina "vaguedad», que vendría a ser el desatendimiento de la transición de las relaciones sintácticas de la experiencia estética. Se produce por ejemplo cuando se atiende únicamente a los detalles pero se desatiende el contexto o la estructura más formal que lo sustenta. Puede ocurrir también al contrario, que de ser la obra inaprensible en su contexto no seamos capaces sino de captar detalles y texturas a las que no podemos agarrarnos. Ahora bien, ¿es necesariamente una «vaguedad"?, ¿y si tal desatendimiento es su más sincera intención? En ocasiones ha podido parecer que el arte contemporáneo ha querido traspasar esta barrera o limitación, queriendo habitar un limbo o tierra de nadie. $Y$ en ocasiones es cierto que tal escapada o descuido, a propósito o no, del equilibrio modal ha supuesto una ruptura del arte como medio homogéneo, en términos de G. Lukács. Afirma Jordi Claramonte en relación con la visión de este último que lo peligroso del arte contemporáneo, al disolverse con la vida cotidiana, es que muchas veces pierde esa densidad específica del medio homogéneo, esa capacidad de ser transportados. Es decir, en términos modales, pierde potencialidad como modo de relación.

Lukács defiende que un medio homogéneo es aquel modo de relación capaz de concentrar nuestra percepción en algo concreto, en dirigir nuestra atención hacia lo que percibimos. Es decir, focaliza nuestra atención estableciendo una consistencia o permanencia en el objeto o realidad artística. El arte en tanto medio homogéneo es capaz de transformarnos a partir de su "realidad intensiva ${ }^{27}$. Para ello, a pesar de no abarcar la totalidad de las ciencias, sino inquietudes más particulares, trama

25 Ibidem, p. 165.

26 Ibidem.

${ }^{27}$ A diferencia de la ciencia, para Lukács, que tiene una totalidad extensiva, es decir, que pretende acoger la totalidad de nuestra realidad desde la cosmología hasta lo molecular a partir de su magnitud y complejidad, el arte remite a una totalidad intensiva. Con ello se quiere decir que el arte reconoce y construye totalidades particulares cuyo carácter parte de estar acotado y definido, de trabajar con elementos concretos. 
desde lo cotidiano todo un mundo (temporalmente) posible. Las vanguardias y arte contemporáneo en tanto dialécticas negativas, al partir de situaciones cotidianas, pueden correr el riesgo, si no está bien tramada su sensibilidad estética, de resultarnos insignificantes o incapaces de movernos categorialmente, suspendiendo posiblemente la categoría de la apate.

Otro de los motivos que podría acusar Lukács de las vanguardias y su ruptura de homogeneidad es que su disposicionalidad de tan abstracta sea inaprensible. Leonard B. Meyer afirma: «Puede suceder que si en ese equilibrio que es toda composición se elimina excesivamente la redundancia, un conjunto de patrones relacionales que nos sea medianamente familiar, se nos impide responder a los estímulos y se nos acaba expulsando del juego $»^{28}$. Algunas de las nuevas corrientes conceptuales de la danza contemporánea han sido fieles a este manifiesto, desarrollando desde la abstracción unos contenidos concretos y a menudo difusos. En términos modales, es como si el arte, en la lucha por la autonomía, se hubiera quedado encerrado en la lucha y no hubiera tenido en cuenta el contagio de tal autonomía y, como ha ocurrido antes, ser ininteligible o inaprensible. A este fenómeno desafortunado, de repertorialidad privada, lo llama Meyer la incertidumbre indeseable.

No obstante, como decíamos parafraseando a Fratini, la danza contemporánea, a pesar de haberse negado a sí misma, haberse heterogeneizado, nunca lo ha hecho lo suficiente como para desaparecer. Se encuentra en esta tensión. El desatendimiento del carácter formal ha supuesto en ocasiones nuevas formas de mirar y apreciar el arte. Como veíamos anteriormente, Yvonne Rainer introduce desde la no danza la sensación de agotamiento de la danza, no necesariamente como nihilismo o negación de su ser, sino como aprehensión crítica de esta, como intento de revitalizamiento y como motor de búsqueda. Al introducir nuevos elementos cotidianos a la danza, la ausencia de música o la quietud, se pone en cuestión la ontología de la misma, la identificación con una idea de verdad que se había hecho propia. Mediante el modo de lo posible se propone una nueva ontología en la que se cuestiona qué es la danza, desde su conocimiento y su desconocimiento, exigiendo también al espectador establecer un nuevo modo de mirar. En este sentido, podemos, sin olvidar a los clásicos y el peso repertorial del pasado, jugar con nuevas disposicionalidades y modos de entender nuestro contexto y a nosotros/as mismas.

La introducción de estos nuevos elementos disposicionales ha posibilitado además nuevos discursos escénicos de lo transdisciplinar. Como afirma José A. Sánchez, "los intérpretes han dejado de ser meros ejecutores para convertirse en personas que piensan con su cuerpo $»^{29}$. Yvonne Rainer es ejemplo de ello. En una de sus primeras piezas, Trio A. La mente es un músculo, se refleja ya no solo una reivindicación al panorama de la danza postmoderna sino al modo en el que se concibe la condición ontológica de los/as bailarines, defendiendo que la danza es también

28 Ibidem, p. 158.

29 SÁnchez, J.A. (1999). «Pensando con el cuerpo», en SÁnchez, J.A. (ed.), Desviaciones, (pp. 13-28), UCLM-ARTEA, Madrid-Cuenca. 

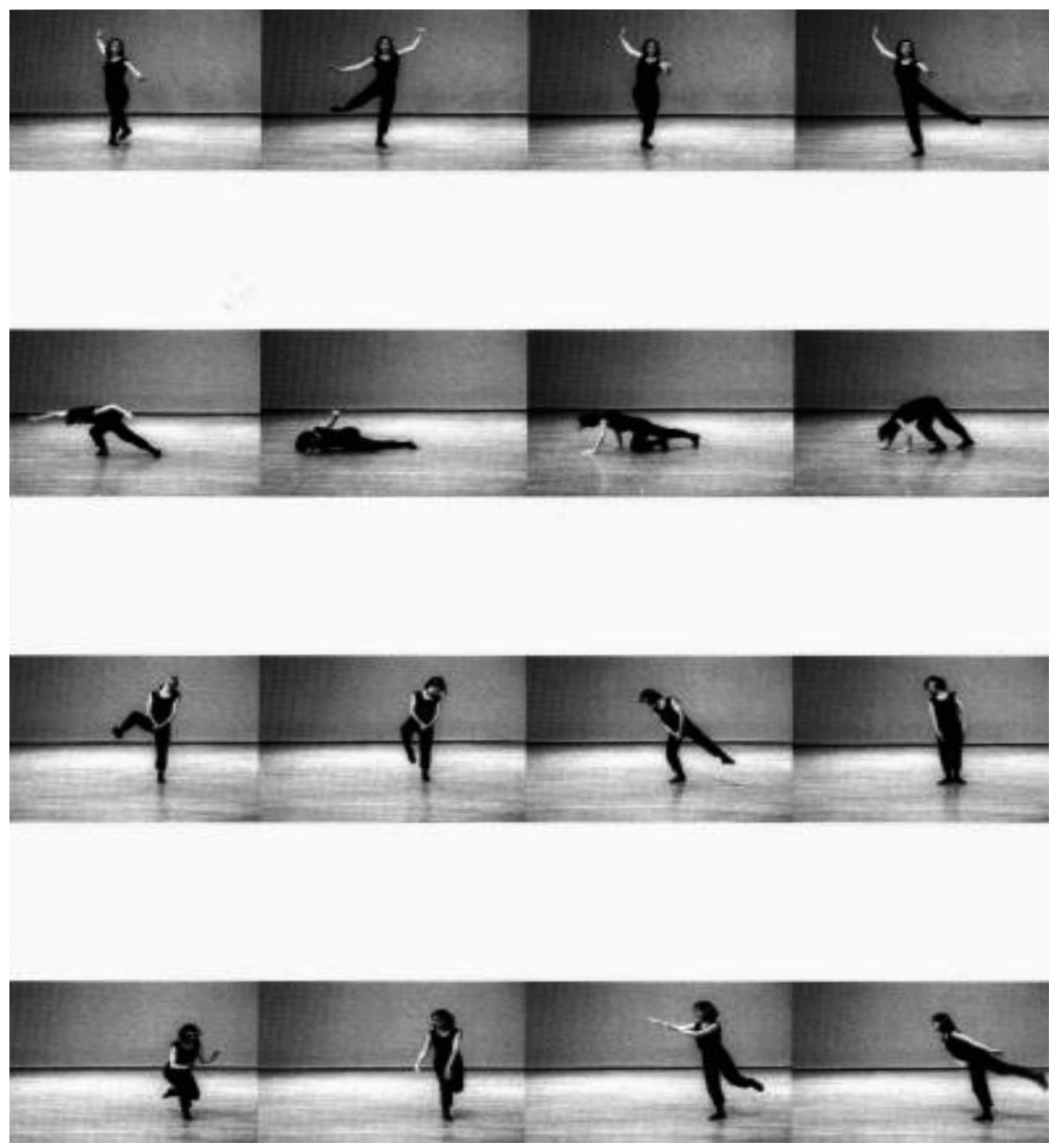

Y. Rainer. Trio A. 1978.

Cinematografia por Raubert Alexander.

un método de autoconocimiento y un modo de pensamiento. "Lo que en todos estos años no ha desaparecido es la idea de que la danza puede ser algo más que una composición armónica de movimientos destinada a ilustrar la música, agradar a la vista o sorprender con sus retos a las limitaciones físicas del común de los mortales» ${ }^{30}$.

30 Ibidem. 
Yvonne nos conecta especialmente con la visión de la fenomenología deconstructivista francesa e incluso las visiones de la neurología moderna al afirmar que la mente es un músculo y el pensamiento es algo que circula por el cuerpo, desvirtuando las lecturas metafísicas y herméticas de la razón humana. En esta pieza en concreto, The mind is a muscle (1973), está especialmente presente la búsqueda de cómo ligar movimientos cotidianos y no cotidianos para formar una danza, sin necesidad de música o ritmos que vengan determinados desde fuera de la propia danza. La búsqueda por el movimiento se convierte en la premisa principal y para ello se nutre de la investigación sobre la duración, el conteo, el tempo, la pausa, así como rutinas que nos fijamos a nosotros/as mismas. La misma Yvonne Rainer afirmaba: «It is about going through the motions». Paradójicamente anulando la ilusión estética y el sentido del espectáculo, como espectadores somos atrapados y transportados por el movimiento de un modo cuidadoso y minimalista: el juego de las formas, los cambios de peso, los gestos, el minimalismo, su aparecer y su transformación. Esta cuidadosa manera de trabajar, de plasmar la comunicación directa entre pensamiento y cuerpo, se convertirá en un nuevo campo de práctica, así como curiosamente bajo la intención de huir de un modo de lo repertorial, la pieza se configura en un repertorio en tanto que se abre como dispositivo para poder ser reproducido, desarrollado y ejecutado.

De este modo se refleja que lo que antecede a la danza es la cotidianidad, la franca realidad de la que partimos, también lo/as bailarines. Así la danza se encuentra profundamente inspirada y comprometida a cuestionar los dos mundos paralelos, la escena y el mundo cotidiano, y hacer consciente la relación que existe entre la investigación y el pensamiento. En este sentido encontramos en Yvonne, además de una referente política e ideológica, una revolucionaria hacia los modos de construir una estética en la danza rompiendo con elementos que han sido claves, como el modo tradicional de experimentar la ilusión estética. No obstante, si entendemos la ilusión estética de un modo más relacional, no desaparece necesariamente. Inevitablemente la apate interviene en ese juego al que se nos invita, aunque sea por ínfimos momentos, sugiriéndonos que hay algo de distintivo entre lo que vemos bajo tal experiencia y un mundo externo de preconceptos. Como explica J. Claramonte, toda experiencia estética se compone de dos juegos, de aquello que hemos contemplado bajo la repertorialidad como la mímesis y lo que implementamos, la poiesis. A pesar de que la pretensión de Yvonne haya sido huir de un repertorio, la base de su impulso disposicional parte del propio repertorio, aunque sea para negarlo.

Afirma Magda Polo sobre la situación de la danza moderna: «El cuerpo empieza a plantearse su presencia reflexiva cuando ya no se centra en la exaltación de la forma y el pensamiento, cuando ya no es espectáculo, cuando ya no es imagen sino un cuerpo que genera discurso. Cuando el cuerpo se libra de su histórica condición de ser mirado, se experimenta un agotamiento de los recursos de su representación, de los recursos miméticos, se experimenta un agotamiento de la danza» ${ }^{31}$.

31 Polo, M., Fratini, R., Raubert, B. Filosofía de la danza, Univ. Barcelona, 2015, pp. 14-15. 
Las artistas postmodernas nos darán pie a reflexionar en claves contemporáneas que la relación clásica de sujeto genera objeto y de artista hace obra no es la única posible. Es posible generar nuevas relaciones o incluso invertir el proceso. Sin embargo, lo que no podríamos olvidar es el atendimiento minucioso de las partes y del todo.

\section{- NeCESIDADES: LO BÁSICO Y LO SINGUlAR}

Para referirnos a este atendimiento minucioso es pertinente rescatar el concepto griego, tan vital, imprescindible y en ocasiones tan ausente en nuestros tiempos de eulabeia. El término está insertado también en la estética modal y está relacionado con un cuidado que se dispone a aquello que hacemos con un proceder con atención. Alude genéricamente tanto al modo de organizarnos, de experimentar nuestras vidas y deseos particulares, como de contemplar una obra de arte. Es curioso que ya por el año 1926, en el prólogo de la Ética, Hartmann anunciara que el mundo es un mundo apresurado y que el hombre moderno al ir con esta prisa no es capaz de prestar atención, de ver los fenómenos tal como son. Este hecho no es solo útil a la hora de fundamentar su teoría ética, sino que es un modo o condición de ser profundamente estético. Ser capaces de atender con cuidado a nuestros semejantes y a las cosas que hay en el mundo es vital para poder tener una experiencia estética de algo. Las condiciones para que pueda darse están tanto en el sujeto como en el objeto, así como sobre todo en las relaciones intermodales que los conectan, por ello decíamos que el propio artista no puede producir valores, sino que los posibilita.

La eulabeia rescata aquello que Fratini ha referido como la "paciencia poética» y que está tan ausente en nuestras sociedades de la impaciencia. La eulabeia tiene en sí misma una admiración a la realidad, a los seres que participan de tal realidad, y alimenta, más que una riqueza o abundancia, una economía de elementos. Por tanto, aquello que interviene directamente con lo que generamos como comunidad estética debe estar orientado bajo nuestra sensibilidad. El cuidado debe estar tramado por igual, afirma J. Claramonte, tanto en su modo necesario como en el de lo posible, tanto al definir un sentido como en el juego de las relaciones. La atención del que experimenta como del que acepta sus necesidades debe estar presente, «sabiendo que los acontecimientos y desacoplamientos entre lo disposicional y lo repertorial, entre lo que sigue patrones y lo que ofrece sorpresa acontecerán siempre en el paisaje epigenético de la complejidad, de lo efectivo, concebido como matriz de conflictos, como campo de batalla modal ${ }^{32}$.

De un modo desvergonzado podríamos decir que la eulabeia contiene en sí misma amor. Y aquí es necesario entender la palabra Amor. Me gustaría defender el concepto a partir de La danza del futuro ${ }^{33}$, de Jaime Conde Salazar. En su último

\footnotetext{
32 Ibidem, p. 309

33 Conde Salazar, J. La danza del futuro, op. cit.
} 
apartado comienza enunciando: «Hagamos el esfuerzo de pensar en el Amor más allá de las narrativas heteronormativas hegemónicas que nos condenan y nos limitan a una especie de romanticismo absoluto, sin escapatoria», añadiendo: "Esos seres transitorios que se producen en el $\mathrm{Amor}^{34}$ (llamémosle objetos artísticos) revelan dimensiones de la realidad que permanecían ocultas y muestran posibilidades infinitas de transformación del mundo $»^{35}$. La eulabeia es por tanto un acto de amor hacia el mundo, en tanto que nos disponemos a la escucha y al cuidado de lo que hacemos, valorando no solo lo que necesita o «le falta», sino lo que ya hay.

Olvidamos que la apreciación del arte y de eso que denominamos cultura no es más que experiencia, en su sentido más «encarnado» y literal, y que para que la experiencia tenga lugar debe haber tiempo vivencial. El panorama actual se encuentra saturado en gran medida por este fenómeno de dispersión y multidireccionalidad en el que es necesario un elemento simple, la paciencia. A este fenómeno contemporáneo Roberto Fratini lo llama «las liturgias de la impaciencia». Lo que realmente estamos olvidando es que cualquier acto artístico está íntimamente relacionado con la paciencia, con que cada proceso tiene su tiempo, y con la habilidad de aceptar que hay cosas que no pueden explicarse o que no tenemos el derecho de explicar. Lo que Fratini reclama es que la audiencia, así como el mismo artista, está perdiendo la aceptación de que el arte tiene algo de inhóspito, incluso para el propio artista, y que por tanto no podemos hacer una inmediata comprensión o apreciación. El/la artista debe trabajar bajo «la paciencia poética», afirma. Él mismo define la «paciencia poética» bajo los siguientes términos: "I can't but do what I'm doing even if I don't know why I'm doing it, since I don't know it exactly I don't need to give an exact explanation and I sure have the right not to give those explanations because the poetical gestures begins when I accept that my work of art will be more intelligent than me» ${ }^{36}$.

Bajo esta indeterminación, presente y futura, del artista frente al proceso creativo, Fratini libera de algún modo las tensiones y exigencias del capitalismo cultural, así como las supuestas libertades que este aporta. Mediante valores simples perdidos nos invita a retornar hacia lo necesario. Además, es desde este acto de confianza y de liberación del artista sobre su propia autoría desde donde puede generarse un proceso de investigación artístico. El discurrir de la poética emergente es el camino para que más tarde se dé, o no, una significación del resultado. En términos modales, el arte debe ser un medio de autoorganización capaz de generar relaciones.

${ }_{34}$ Aquí podríamos incluso cambiar el concepto Amor por eulabeia.

35 Conde Salazar, J. Op. cit., p. 95.

36 Fratini Serafide, R. (abril de 2015). Arts of an ending. (UN)CONFERENCE organized by Tanzquartier Wien and EDN (European Dancehouse Network), Viena. 
La realidad debe ser entendida desde la praxis y la praxis humana sensible no puede sino ser - porque no queremos otra, claro está- autopoiesis, autoogranización. Para que algo merezca el alto nombre de praxis humana sensible tiene que producirse desde y hacia la autonomía ${ }^{37}$.

Aquí es necesario indagar un poco más en eso que hemos estado inevitablemente estableciendo o invocando: la idea de autonomía en el arte. Al hablar de la tensión diamantina y de las interrelaciones generativas, para poder comprender la dispersa y compleja situación en la que se encuentra el arte contemporáneo, necesitaremos acudir a la lucha que viene estableciéndose desde incluso antes de la Ilustración y que ha ido modificándose hasta nuestros días. En especial queremos rescatar el término autonomía modal para defender un modo de comprender o apreciar las piezas como entes en cierto modo autónomos. Esto implica, y para no caer en el error de la autonomía moderna, que la contemporaneidad, como bien explica Jordi Claramonte en La República de los fines, debe vérselas con las exigencias actuales. Para ello nos centraremos brevemente en rescatar sus tesis centrales:

La autonomía modal debe seguir manteniendo la negatividad que caracterizaba la autonomía moderna; ahora bien, en tanto que la situación ha cambiado y hemos podido aprender de algunos errores que podemos apreciar bajo la reflexión teórica, es necesario cuestionarnos qué cambios debemos introducir. La modernidad y el resultado de las vanguardias se encontraron en un periodo de cambio, transformación y experimentación, pretendiendo desmitificar la idea aurática del arte de Benjamin y disolviéndolo en la vida cotidiana. Lo importante aquí es destacar, en palabras de J. Claramonte, que «al capitalismo tardío ya no le molesta la diferencia: estamos en la era del consumo de masas personalizado ${ }^{38}$. El discurso de la oposición, aquello que fue reaccionario en un momento vital para la historia del arte, o bien quedó hermético y reducido a un pequeño grupo de artistas que podían desarrollarse y entenderse por el hecho de compartir un repertorio, o se comercializaron y se normalizaron aquellos intentos de distinción y diferenciación.

Otra de las características de la autonomía moderna, y que en ocasiones seguimos aún reproduciendo, es la exaltación de la subjetividad, de los/as artistas como individuos creativos al margen de ser parte de un sistema político y económico. Este modelo individualista ha sido, sin reparos, defendido por el propio sistema capitalista dando lugar a nuevas necesidades como el ser autónomos, emprendedores, etc. Ahora bien, paradójicamente esta visión de la autonomía no es más que un reciclaje de nuestros deseos por desprendernos del pasado y de emprender un camino en solitario, más que nunca apoyado por el Régimen. Entendemos por diversos motivos que este formato nos aleja de una definición modal de la estética y nos impide poder

37 Claramonte, J. Estética Modal, p. 308.

38 Claramonte, J. La República de los fines, p. 181. 
explicar en claves actuales el marco de comprensión que necesitamos. Entonces, ¡en qué sentido hablamos de negatividad?

Quizás lo interesante, rescatando la propuesta de la autonomía modal, sea pensar las «mediaciones a través de las cuales esa autonomía cobre sentido transformador, cuales sean sus vasos comunicantes ${ }^{39}$. Debemos contar por tanto con una idea de la negatividad que sea capaz de aceptarse a sí misma como cambio, que sea, más que rebelde, sabia. Tal potencia radica en no estar encerrada en su negación, en ser capaz de buscar alternativas y conexiones entre aquello que puede aportar también una positividad, en términos siempre modales. Mediante la negatividad no se pretende focalizarnos únicamente en la creación de obras, y aquí retomamos la aportación de J. Conde Salazar, sino en la posibilidad de generar procesos. La acción pragmática de los procesos artísticos asume ser transformadora y relacional basándose «en la investigación y la experimentación de otros modos de relación, otros modos de hacer que no hagan juego ni a la mercantilización ni a la estetización capitalista de las vidas y el mundo" ${ }^{40}$. Por tanto es una negatividad que se dispone a sí misma al futuro sin negar el pasado, partiendo de la reflexión de este para determinarse. Esta idea de autonomía, a pesar de ser consciente de las fuertes presiones del régimen capitalista, se pretende construir articulando espacios de cohesión y estableciendo modos de relación. A partir de esta necesidad dialéctica se desarrolló también eso que Wittgenstein llamó «juegos de lenguaje» y John Berger «modos de ver»; en definitiva, supone pensarnos y situarnos en un lugar intermedio de la discusión subjetivo-objetiva, sin precipitarnos desesperadamente por las dinámicas capitalistas ni quedándonos únicamente en el plano normativo, ya que quedarnos anclados a la discusión sobre el dualismo es como quedarnos atrapados por el relativismo.

Un aspecto imprescindible y que posiblemente han olvidado o dado por sentado las demás luchas por la autonomía y el propio poder opresor es el carácter corporal del sujeto que moviliza tal idea, que cuerpo y pensamiento no son entidades diferentes, sino profundamente entretejidas. Este planteamiento justifica especialmente la defensa de nuestra tesis: el punto de partida de un pensamiento modal debe partir del "carácter situado» y "su enraizamiento en un cuerpo", como defiende Claramonte a partir de John Dewey. La estética, entre sus muchas funciones, debe servir para dar cuenta de nuestra sensibilidad en tanto cuerpos relacionales. En términos de Claramonte, acercándose mucho a Merleau Ponty: «Se trata con ello de salvar una de las escisiones más hirientes para todo pensamiento estético, la que se ha instalado entre nuestra sensibilidad y nuestro arte, la escisión que cree posible pensar desde claves meramente intelectuales o verbales, desgajadas del cuerpo y la sensibilidad $»^{41}$. En términos de J. Dewey, especialmente útiles para nuestra reflexión filosófica sobre la danza: «La experiencia estética, por definición, está siempre «desbordando" (spilling over), es decir, fluyendo y contaminando otras áreas de experiencia

\footnotetext{
39 Ibidem, p. 183.

40 Ibidem, p. 186.

${ }^{41}$ Ibidem, p. 195.
} 
que en principio quedaban fuera de su alcance, modificando los parámetros de la percepción y el entendimiento, interviniendo las relaciones ${ }^{42}$. La negatividad de la autonomía que la caracteriza no recae entonces en su mera oposición sino en su toma de distancia para precisamente ser capaz de vincularse de modo crítico tanto con lo político como con lo cotidiano. Es por ello por lo que hemos destacado el trabajo de Yvonne Rainer, por haber sido capaz de oponerse a una visión "aurática» de la danza y haber jugado modalmente a tramar o fusionar ambos componentes, lo formal y lo cotidiano, sin haberse quedado en un mero discurso político del cuerpo ni reproduciendo o introduciendo mediante la danza únicamente patrones o movimientos cotidianos.

Entendemos por consiguiente que tanto en la creación artística como en la experiencia estética no tiene sentido seguir manteniendo una noción de sujeto desvinculada del objeto y viceversa. Al defender la presencia de conceptos relacionales, los términos de objetividad y subjetividad pierden sentido. Por ello, aceptar la autonomía modal implica aceptar también cierta dependencia. Jordi Claramonte define la autonomía en los siguientes términos: «La autonomía o es contagiosa o deja de ser autonomía para convertirse en privilegio ${ }^{43}$. Esta dependencia radica tanto a nivel más genérico, en la forma de concebirnos como seres políticos y artísticos en tanto comunidad, como en los modos de dependencia que están operando para poder cohesionar y establecer una apreciación o experiencia estética de algo determinado.

Retomando la visión de Fratini sobre la paciencia poética, la conformación de estos elementos que asientan (en términos modales que tienen un carácter repertorial) no puede darse de modo apresurado, como han pretendido muchos teóricos al generar una lectura directa o clasificación de ciertos artistas imponiendo clasificaciones o estilos, sino que, como toda tradición, necesita de tiempo de desarrollo y reposo. Ante esta urgencia por la renovación y a su vez la lucha por la autonomía podemos seguir manteniendo la idea de Lukács desde la visión de la estética como una triple teoría: una teoría del arte, una teoría de la sensibilidad y una teoría de la performatividad social y práctica. ¿De qué modo el arte puede integrar estos aspectos?, ¿¿n qué sentido estos elementos se relacionan? El objetivo de la estética, en términos de Jordi Claramonte, parte de acometer esta recuperación de lo estético en toda su potencia, investigando la consistencia y la lógica de los procesos y de autoorganización. Para ello se convierte en necesario abrir paso a que el arte pueda ser medio para significar otros aspectos, partiendo de su carácter comunicativo aunque valorando otras posibles funciones. Asumimos por ello que debe haber un contagio del arte a otras esferas y que este debe darse desde un contagio con otras esferas. En último término lo que nos interesa es aquello a lo que podemos denominar generativo, aquello que emerge y depende de los propios procesos de autoorganización, aquello que ocurre tanto en la naturaleza como en el arte, y no de un dios o un creador demiurgo, sino de las tensiones de autonomía y dependencia que se entretejen en el conjunto.

\footnotetext{
42 Ibidem, p. 198.

43 Claramonte J. Estética Modal, p. 15
} 
En términos de J. Baudrillard: «El problema del arte no es que haya muerto, sino que este no puede morir». Con ello queremos referir a las inevitables resonancias o permanencias que el arte incluso en su forma más efímera es capaz de dejarnos. Lo especial y esperanzador, incluso cuando la danza parece agotarse, es pensar su posibilidad de crear mundos posibles, de mostrarnos a partir de lo «irreal» algo «real», o incluso, mostrarnos un reflejo de aquello que continuamente vemos y no nos hemos detenido en observar.

Recibido: octubre de 2018, ACEPTADo: noviembre de 2018 